\title{
Theoretical assessment of evaporation rate of isolated water drop under the conditions of cooling tower of thermal power plant
}

\author{
Sergey Shevelev ${ }^{1, *}$ \\ ${ }^{1}$ National Research Tomsk Polytechnic University, 634050 Tomsk, Russia
}

\begin{abstract}
The purpose of the work is numerical modelling of heat and mass transfer at evaporation of water drops under the conditions which are typical for a modern chimney-type cooling tower of a thermal power plant. The dual task of heat and mass transfer with movable boundary at convective cooling and evaporation for a 'drop-humid air' system in a spherical coordinate system has been solved. It has been shown that there is a rapid decline of water evaporation rate at the initial stage of the process according to temperature decrease of its surface. It has been stated that the effect of evaporation rate decrease appears greatly in the area of small radiuses.
\end{abstract}

\section{Introduction}

Today cooling towers are the cheapest way of low potential heat transfer from steam turbine plant condensers in schemes of thermal and atomic power plants (thermal power plant and atomic power plant). Increase of pressure in a condenser of steam turbine plant at $0.001 \mathrm{MPa}$ from nominal value at other permanent parameters decreases electric power at $0.6-1 \%$. Thus, on the whole, cost effectiveness of a power plant greatly depends on operational efficiency of a cooling tower. Besides, their exploitation allows saving up to $95 \%$ of fresh water [1].

The function of a cooling tower is to cool flow of water entering it. In modern cooling towers used at thermal power plants and atomic power plants this can be achieved via heat transfer from heated water drops to cold atmospheric air at their mutual motion. Water cooling mainly occurs because of convection and surface evaporation. The role of irradiation in the conditions specific for modern energetic cooling towers is small and, as a rule, is not taken into consideration at calculations. The ratio between a quantity of heat transferred by convection and evaporation is enormously determined by external factors. In the hot summer evaporation of heat evaporated by water is up to $90 \%$ and more and in cold winter months heat transfer by convection can reach $50 \%$ [1]. Formed water vapor mix with atmospheric air and heat it up thus worsening the conditions of cooling water. Evaporated part of cooled water is taken away from a cooling tower with atmospheric air stream. This water relates to losses as it is irrevocably lost in the atmosphere and needs replenishment

\footnotetext{
*Corresponding author: wevelev@,tpu.ru
} 
from the external source. Thus, it can be said that there is enormous negative influence of the process of surface evaporation of drops on cooling tower efficiency which appears in heat transfer worsening between heated water and cooling air and also in transfer of formed water vapor with atmospheric air. A choice of such modes of cooling towers work and also parameters of drops which provide minimal quantity of evaporated water and its maximum cooling represents a considerable interest.

Choice of effective modes of water drops cooling is possible at mathematical model creation which adequately defines the processes of heat and mass transfer at water evaporation under the conditions of drops moving in cooling towers. Nowadays there are no theories fully describing the accompanying processes.

The main factor determining water evaporation rate and quantity of removed moisture, accordingly, is different pressures of saturated vapor and vapor close to evaporation boundary [2]. Size of drops is also important for determining surface area. Influence of different sizes of drops on their evaporation rate in conditions typical for a standard powerful cooling tower used at modern thermal power plants and atomic power plants has a great importance for studying it nowadays.

The present work presents the results of numerical modelling of heat and mass transfer at water drop evaporation under the conditions which are typical for modern cooling towers of thermal power plants.

\section{Formulation of the problem}

The problem under consideration was heat and mass transfer at cooling of an isolated spherical water drop in air stream under the conditions typical for very effective modern cooling towers. It was supposed that a drop moved in the area filled with humid air. The initial temperature of a drop $T_{0}$ was a shade higher than the temperature of humid air $T_{\text {air }}$ (at $15 . .30^{\circ} \mathrm{C}$ ). Cooling of a drop occurs at convection and also because of vapor formation (evaporation) on the boundary of phase change 'water drop - humid air'. Furthermore, the function of irradiation is small and it can be neglected [1]. Formed water vapor is blown into humid air and mix with it. Dimensions of a drop decrease at vapor formation.

Deformation of a drop is possible in real conditions of drop motion under the influence of forth of gravity. It has been experimentally stated [3, 4] that a drop is continuously deformed in the air, gradually obtaining different forms (sphere; ellipsoid, driven in the direction of travel; ellipsoid, driven in cross direction, 'pancake' etc.). Therefore, as a result of the problem statement acceptance of a spherical form of a drop is as much relevant as any other.

Thermophysical parameters of water and air were accepted regardless of temperature. Gaseous atmosphere is binary (a mixture of air and water vapor).

Scheme of region of problem solution is shown in figure 1.

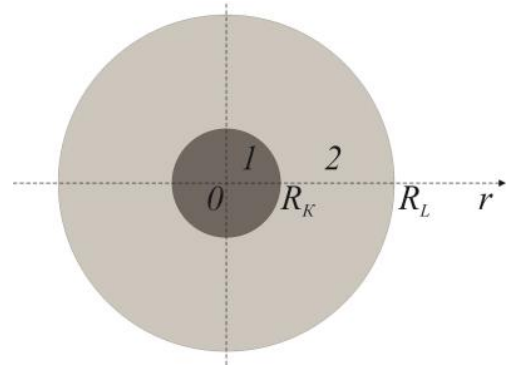

Fig. 1. Scheme of region of problem solution. 1 - water drop, 2 - humid air. 
The process of heat and mass transfer the conditions of which are under consideration can be described with the help of the following system of differential equations in differential coefficient, written in spherical coordinate system:

$$
\begin{gathered}
\rho_{1} c_{1} \frac{\partial T_{1}}{\partial t}=\lambda_{1}\left(\frac{\partial^{2} T_{1}}{\partial r^{2}}+\frac{2}{r} \frac{\partial T_{1}}{\partial r}\right), 0<r<R_{K} \\
\rho_{2} c_{2} \frac{\partial T_{2}}{\partial t}=\lambda_{2}\left(\frac{\partial^{2} T_{2}}{\partial r^{2}}+\frac{2}{r} \frac{\partial T_{2}}{\partial r}\right), R_{K}<r<R_{L} \\
\frac{\partial C_{\mathrm{w} . v .}}{\partial t}=D\left(\frac{\partial^{2} C_{\mathrm{w} . v .}}{\partial r^{2}}+\frac{2}{r} \frac{\partial C_{\mathrm{w} . v .}}{\partial r}\right), R_{K}<r<R_{L}
\end{gathered}
$$

Here: $T, K$ - temperature; $\rho, \mathrm{kg} / \mathrm{m}^{3}$ - density, $c, J /(\mathrm{kg} \cdot \mathrm{K})$ - heat capacity; $\lambda, W /$ $(m \cdot K)$ - heat conductivity, $C_{w . v .}$ - water vapor concentration, $D, m^{2} / s$ - difusion coefficient. Index 1 is correspondent to a water drop, index 2 - to humid air.

Equations (1) - (3) were solved under the following initial and boundary conditions:

$$
\begin{aligned}
& t=0: T_{2}=T_{\text {air }}, R_{K} \leq r \leq R_{L} \\
& t=0: C_{w . v .}=C_{0}, R_{K} \leq r \leq R_{L} \\
& r=0: \frac{\partial T_{1}}{\partial r}=0 \\
& \left\{\begin{array}{l}
T_{1}\left(t, R_{K}\right)=T_{2}\left(t, R_{K}\right) \\
-\left.\lambda_{1} \frac{\partial T_{1}}{\partial r}\right|_{r=R_{K}}=-\left.\lambda_{2} \frac{\partial T_{2}}{\partial r}\right|_{r=R_{K}}+Q W,
\end{array}\right. \\
& r=R_{L}: \frac{\partial T_{2}}{\partial r}=0 \\
& r=R_{K}:-D \frac{\partial C_{w . \mathrm{v} .}}{\partial r}=\frac{W}{\rho_{2}} \\
& r=R_{L}: \frac{\partial C_{\mathrm{w} . \mathrm{v} .}}{\partial r}=0 .
\end{aligned}
$$

Here $Q, J / \mathrm{kg}$ - heat of phase change; $W, \mathrm{~kg} /\left(\mathrm{m}^{2} . \mathrm{s}\right)$ - evaporation mass rate, found by applying the formula [2]:

$$
W=\frac{A\left(P_{S}-P\right)}{\sqrt{2 \pi R T_{\text {bound }} / M}},
$$

where $A$ - accommodation coefficient, $P_{S}, P a$ - saturated water vapor pressure, $P, P a$ - vapor pressure close to evaporation boundary, $M, \mathrm{~kg} / \mathrm{kmol}$ - molecular mass of water, $T_{\text {bound }}, K$ - temperature of a drop close to evaporation boundary. Accommodation coefficient is found according to the following data [5].

System of equations (1) - (3) was solved upon the application of the finite-difference method [6] by means of implicit difference scheme use. Nonlinear equations were solved by means of iteration method [7], different analogues of differential equations and boundary conditions by applying elimination method by utilizing analogous algorithm [7]. Motion computation of a boundary was made by applying evaporation front tracking in space network node.

It should be noted that the solution of the defined problem is complicated as there is a movable boundary and breakup of heat conduction coefficient on it. That is why we used 
the algorithm [7] with a second-order approximation for boundary conditions of the forth type on the boundary. Besides, time stem of difference mesh was chosen so that to implement a balance of heat when leaving the stationary mode.

\section{Results and discussion}

The problem was solved with the following basic data:

$R_{K}=1,0-5,0 \mathrm{~mm} ; R_{L}=100 \mathrm{~mm} ; \lambda_{1}=0,599 \mathrm{~W} /(\mathrm{m} . \mathrm{K}) ; c_{1}=4183 \mathrm{~J} /(\mathrm{kg} . \mathrm{K}) ;$

$\rho_{1}=998,2 \mathrm{~kg} / \mathrm{m}^{3} ; \lambda_{2}=0,0283 \mathrm{~W} /(\mathrm{m} . \mathrm{K}) ; c_{2}=1005 \mathrm{~J} /(\mathrm{kg} . \mathrm{K}) ; \rho_{2}=1,205 \mathrm{~kg} / \mathrm{m}^{3} ; T_{1}=323$

$K ; T_{2}=288 K ; D=0,0026 \mathrm{~m}^{2} / \mathrm{s} ; C_{0}=0,022$.

Typical radial temperature distribution on a drop is shown in figure 2 .

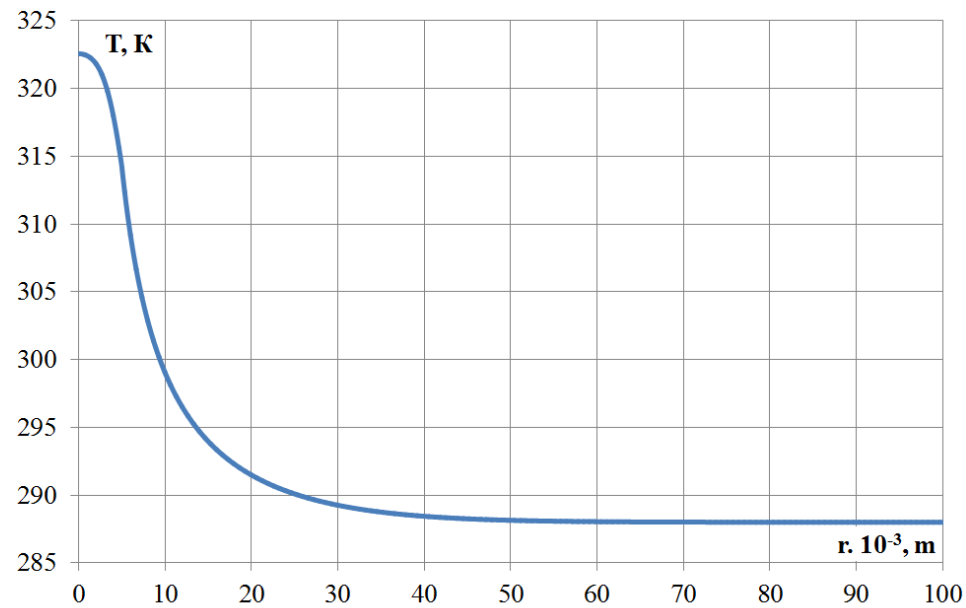

Fig. 2. Temperature distribution in a 'drop-humid air' system at $t=10 \mathrm{~s}, R_{K}=5 \mathrm{~mm}$.

Analysis of temperature change of a drop in the process of cooling it allows concluding about great temperature gradient along a radius of a drop (figure 2). It follows that surface temperature of a drop governs the processes of convective heat exchange and evaporation.

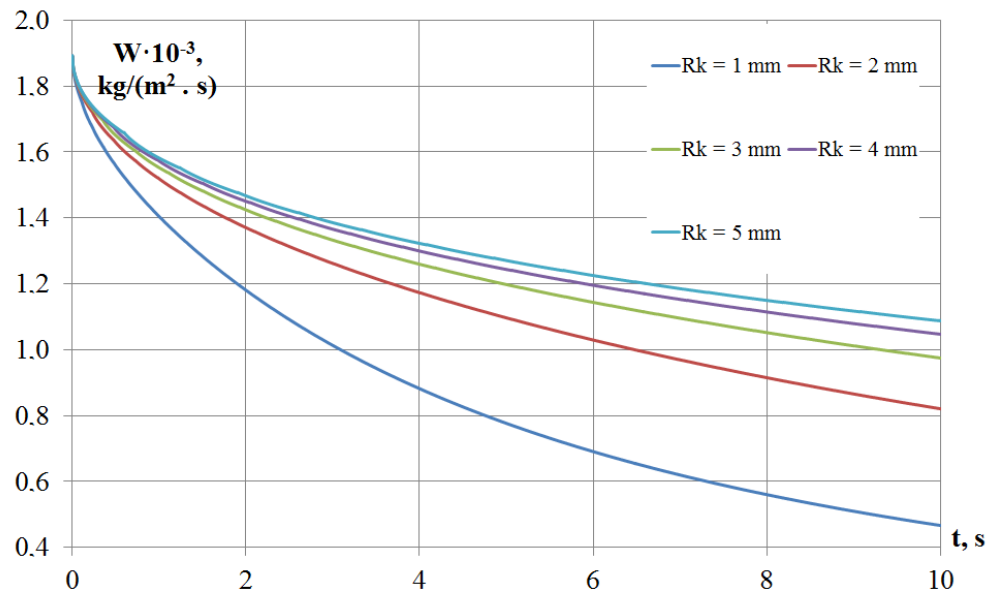

Fig. 3. Time change of drop evaporation rate. 
Dependences of mass rate of evaporation on time for drops of different sizes shown in figure 3 allow us to make the following conclusion. At the initial stage (apart from drop radius) water evaporation rate greatly decreases due to decrease of its surface temperature. Moreover, the less drop radius is the faster its cooling is and, therefore, the more intensively decreases its evaporation rate.

\section{References}

1. V.S. Ponamarenko, Gradirni promyshlennyh $i$ jenergeticheskih predprijatij (Energoizdat, Moscow, 1998) [in Russian]

2. Ju.V. Polezhaev, F.B. Jur'evich, Teplovaja zashhita (Jenergija, Moscow, 1976) [in Russian]

3. R.S. Volkov, G.V. Kuznetsov, P.A. Stizhak, Tech. Phys., 59, 7 (2014), DOI: 10.1134/S1063784214070263

4. G.V. Kuznetsov, P.A. Stizhak, The motion of a manifold of finely dispersed liquid droplets in the counter flow of high-temperature gases Tech. Phys. Lett., 40, 6 (2014), DOI: $10.1134 / \mathrm{S} 1063785014060200$

5. G.V. Kuznetsov, P.A. Kuybin, P.A. Stizhak, High Temp., 53, 2 (2015), DOI: 10.1134/S0018151X15020133

6. Samarskij A.A. Teorija raznostnyh shem (Nauka, Moscow, 1983) [in Russian]

7. P.J. Roache Fundamentals of Computational Fluid Dynamics (Hermosa Publishers, Albuquerque, 2003)

8. G.V. Kuznetsov, M.A. Sheremet, Computational Thermal Sciences, 1, 3 (2009), DOI: 10.1615/ComputThermalScien.v1.i3.60 